\title{
DETERMINATION OF POWER MILL SPENT ON THE CREATION OF THE LONGITUDINAL MOTION OF THE GRINDING LOAD
}

\author{
Dr Alexey Alexey Alekseevich Romanovich* \\ Belgorod State Technological University named after V.G. Shoukhov, Russia \\ Dr Bogdanov Vasiliy Stepanovich \\ Belgorod State Technological University named after V.G. Shoukhov, Russia \\ Dr Liudmila Gennadievna Romanovich \\ Belgorod State Technological University named after V.G. Shoukhov, Russia \\ Dmitry Viktorovich Romanischin \\ Belgorod State Technological University named after V.G. Shoukhov, Russia
}

In this article, a method of grinding material stepwise realized in the roller press mill and a ball mill, equipped with energy-exchange units (LEU). It was found that when using a ball mill, equipped with $L E U$, depending on the angle of rotation of the drum periodically changes its load level of grinding media in the chambers, and in the zone of active influence of LEU is lifted and to give them the longitudinal-transverse movement, characterized by, created in traditional mills. The technique of determining the power consumed by the mill is further equipped with energy-exchange units consumed for longitudinal movement of the grinding bodies in the grinding of materials, previously ground to a roller press mill. Presented equation for its calculation. The influence on the additional power consumption of the length of the first chamber, the angle of energy-exchange devices and load factors cameras grinding bodies. Comparative results obtained by experiment and calculations.

Key words: Ball mill, Energy-exchange device, Method of calculation, Longitudinal transverse motion of grinding media

\section{INTRODUCTION}

In the production of binders, different mixes and products among the energy-intensive processes are crushing and grinding of raw materials, which account for about $10 \%$ of the world's electricity. Thus the power consumption increases significantly with increasing fineness of the obtained product. It is known that the energy consumption for the crushing is $10-21 \mathrm{~J} / \mathrm{g}$, and for fine and superfine grinding $360-3600 \mathrm{~J} / \mathrm{g}$.

Therefore, the direction of improving the technology and grinding equipment to reduce the energy intensity of the process is important.

It is known that the production of cement annual volume, which in the world is increasing and now exceeds 2.5 billion tons, the grinding of raw materials and cement, carried out mainly in ball mills, spent from 40 to $70 \%$ of the total electricity spent on the process of cement production [0102]. Development of new issues and improve the efficiency of existing grinding equipment engaged scholars and practitioners both in our country and abroad. In recent decades, the extensive development of technology for production of cement reached in the grinding complex consisting of two units of roller press mill and ball mill (PVI-CMM) [03-04].

\section{THE MAIN PART}

The studies found that the milled material in TSA after forming between the rollers is different from the original, it has the form of a compacted plate (Figure 1,2) and the particles - micro defect structure. This requires special conditions for regrinding in the CMM.

Studies have shown $[07,08]$, previously ground in the PVI material subject to short-term expedient to impact in the first chamber of the mill for deagglomeration pressed plates and the abrasive effects of crushing -grinding load in the second chamber for its final grinding. Such conditions grinding materials can be obtained in a ball mill (CMM), equipped with a paddle by energy de- 
vices (LEU): blade double-acting (linear dynamic range) and elliptical blade segment (LES).

Studies on the experimental setup, including the $\mathrm{PVI}$ and ball mill equipped with a paddle by en-

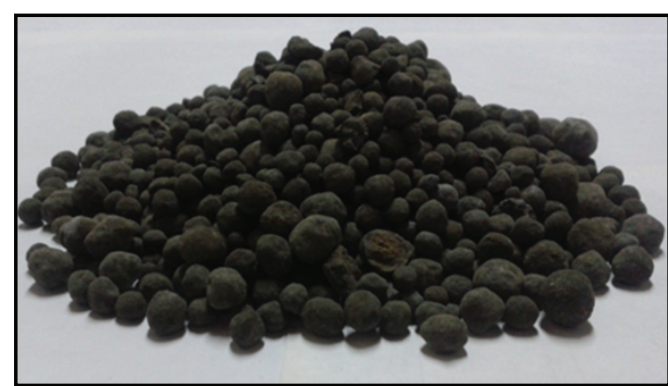

Figure 1: The starting material (clinker) ergy devices diagram is shown in Figure 3, when grinding clinker and additives confirmed the high efficiency of their use.

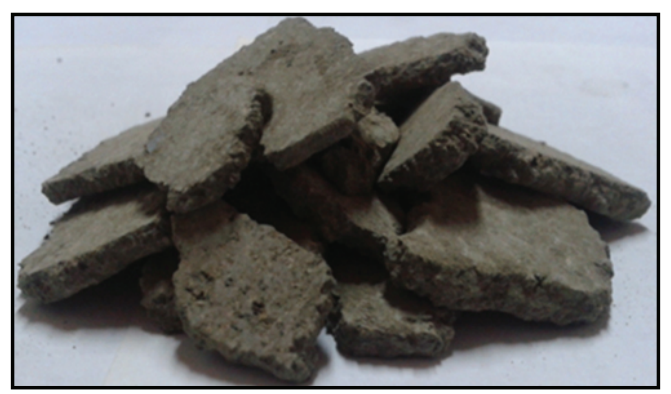

Figure 2. -Klinker after grinding PVI
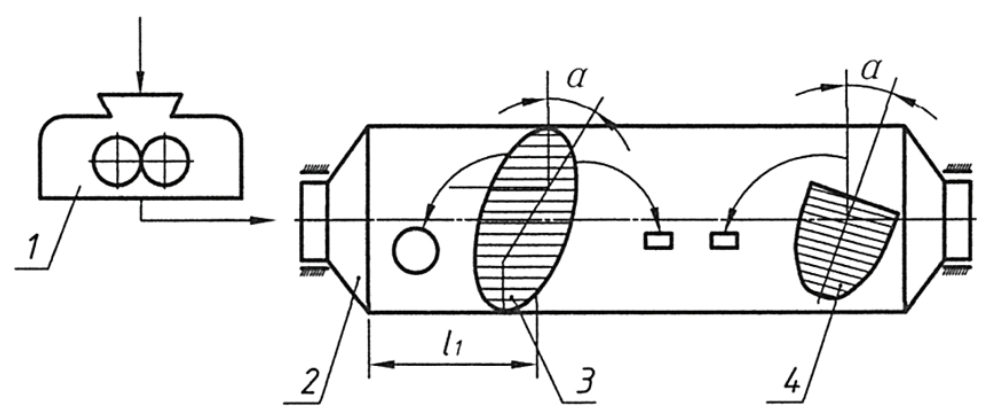

Figure 3. Roller press mill and ball mill, equipped with energy exchange devices: 1 - PVI; 2 - drum; 3 - double action blade; 4 - blade elliptical segment

The mill has increased by $40 \%$. This increase is justified not only by the prior grinding PVI materials, but also due to more work done by the grinding bodies in a ball mill [6]. However, despite the clear advantage over traditional ball mills widespread adoption of CMM with LEU in the industry hampered by the lack of evidence-based methodology for calculating the power consumption of its drive. When using a ball mill, equipped LEU (Figure 4), depending on the angle of rotation of the drum of the mill load level changes periodically grinding bodies in its chambers, and in the active zone of influence LEU - is a "scooping" of grinding bodies with the material being ground, lifting and to give them the longitudinal-transverse movement different from produced in mills without LEU. When this is done the extra work, which consumes power of the engine. Additionally, the power consumption of the mill is associated with a further (compared to the vertical mill with baffles) moving the center of mass loading along the axis of the grinding mill drum by influencing the grinding bodies in the longitudinal direction of the linear dynamic range and LES.
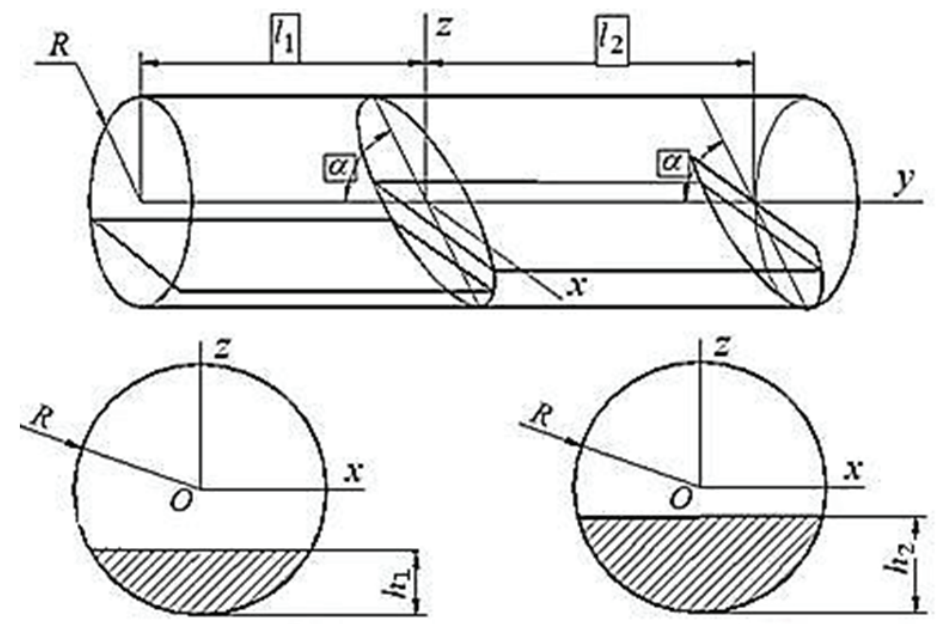

Figure 4: Installation diagram LEU in the drum of the ball mill 
Power for a certain period of time is calculated by the formula:

$$
N=\frac{A}{T},
$$

where - $A$ the work done for the same amount of time $T$.

During the period of time $T$ during one revolution take drum mill when the mill performs $n$, one revolution occurs during:

$T=\frac{1}{n} \min$

or

$$
T=\frac{60}{n} \mathrm{sec} \text {. }
$$

As

$$
n=\psi n_{\text {кр }}
$$

Where $\psi$-relative speed, $n_{\mathrm{Kp}}$ the critical speed. Since

$n_{\mathrm{cr}}=\frac{30}{\pi} \sqrt{\frac{g}{R}}$

where $\mathrm{g}=9.81 \mathrm{~m} / \mathrm{s}^{2}$ - acceleration due to gravity $\mathrm{R}$ - the radius of the drum mill, the formula (3) can be written as follows

$$
T=\frac{2 \pi \sqrt{R}}{\psi \sqrt{g}} \mathrm{sec} \text {. }
$$

In one revolution of the drum mill grinding center of mass loading in each chamber moves from one extreme to the other and back again. For the first chamber to move the center of mass loading per revolution of the drum mill is given by:

$$
S_{1}=2\left|y_{c}-y_{c}^{\prime}\right|
$$

According to [05], $y_{c}$ and $y_{c}^{\prime}$ computed, respectively, by the formulas:

$$
\begin{aligned}
\widetilde{y}_{c} \widetilde{V}_{1}=- & \frac{\lambda_{1}^{2}}{2}\left(\chi_{1} \sqrt{1-\chi_{1}^{2}}+\arcsin \chi_{1}-\frac{\pi}{2}\right)-\frac{2 \lambda_{1} \operatorname{ctg} \alpha}{3}\left(1-\chi_{1}^{2}\right)^{\frac{3}{2}}+ \\
& +\frac{\operatorname{ctg}^{2} \alpha}{8}\left(\chi_{1}\left(1-2 \chi_{1}^{2}\right) \sqrt{1-\chi_{1}^{2}}-\arcsin \chi_{1}+\frac{\pi}{2}\right) . \\
\widetilde{y}_{c}^{\prime} \widetilde{V}_{1}^{\prime \prime}=- & \frac{\lambda_{1}^{2}}{2}\left(\chi_{1}^{\prime} \sqrt{1-\chi_{1}^{\prime 2}}+\arcsin \chi_{1}^{\prime}-\frac{\pi}{2}\right)+\frac{2 \lambda_{1} \operatorname{ctg} \alpha}{3}\left(1-\chi_{1}^{\prime 2}\right)^{\frac{3}{2}}+ \\
& +\frac{\operatorname{ctg}^{2} \alpha}{8}\left(\chi_{1}^{\prime}\left(1-2 \chi_{1}^{\prime 2}\right) \sqrt{1-\chi_{1}^{\prime 2}}-\arcsin \chi_{1}^{\prime}+\frac{\pi}{2}\right) .
\end{aligned}
$$

Move the center of mass loading per revolution of the drum mill in the second chamber is defined by the formula:
$S_{2}=2\left|y_{c 2}-y_{c 2}^{\prime}\right|$

Calculation $y_{c 2}$ and $y_{c 2}{ }^{\prime}$ according to [06] by the formula:

$$
\begin{aligned}
& \tilde{y}_{c 2} \tilde{V}_{2}^{\prime}=\frac{\operatorname{ctg}^{2} \alpha}{8}\left(\chi_{2}\left(2 \chi_{2}^{2}-1\right) \sqrt{1-\chi_{2}^{2}}+\arcsin \chi_{2}-\frac{\pi}{2}\right)- \\
& -\frac{\lambda_{2}^{2}}{2}\left(\chi_{2} \sqrt{1-\chi_{2}^{2}}+\arcsin \chi_{2}-\frac{\pi}{2}\right) .
\end{aligned}
$$

$\widetilde{y}_{c 2}^{\prime} \widetilde{V}_{2}^{\prime \prime}=\frac{\lambda_{2}^{2}}{2}\left(\frac{\pi}{2}-\arcsin \chi_{2}^{\prime}-\chi_{2}^{\prime} \sqrt{1-\chi_{2}^{\prime 2}}\right)+\frac{2 l_{2} \operatorname{ctg} \alpha}{3} \sqrt{\left(1-\chi_{2}^{\prime 2}\right)^{3}}$

Since the work is done by the friction force, then:

$$
A=\left|F_{\mathrm{Tp}} S\right|=F_{\mathrm{Tp} 1} S_{1}+F_{\mathrm{Tp} 2} S_{2}
$$

In turn,

$F_{\text {тр1 }}=f G_{1}=f M_{1} g=f g \gamma V_{1 \text { загр }}=f g \gamma \varphi_{1} V_{1}$

where $f$ - coefficient of sliding friction grinding load on the body of the drum mill; $M_{1}$ - The weight of the grinding load in the first chamber; $V_{\text {1zagr }}$ - The mass of the grinding load in the first chamber; $\gamma$ - Bulk density of the grinding load;

$V_{1}$ - The volume of the grinding load in the first chamber; $\varphi_{1}$ - Load factor milling bodies of the first chamber; $V_{1}$ - The volume of the first chamber.

A similar formula holds for the second camera:

$$
F_{\text {тр2 }}=f G_{2}=f M_{2} g=f g \gamma V_{2 \text { загр }}=f g \gamma \varphi_{2} V_{2}
$$

Since $V_{1}=\pi R^{2} l_{1}$ and $V_{2}=\pi R^{2} l_{2}$ the final formula for calculating the additional power consumption will be as follows:

$$
\begin{gathered}
N=\frac{\psi f g \gamma}{\pi} \sqrt{\frac{g}{R}} \pi R^{2} . \\
\cdot\left(\phi_{1} l_{1}\left|y_{c}-y_{c}^{\prime}\right|+\phi_{2} l_{2}\left|y_{c 2}-y_{c 2}^{\prime}\right|\right)=
\end{gathered}
$$

$$
=\psi f \gamma(g R)^{3 / 2}\left(\phi_{1} l_{1}\left|y_{c}-y_{c}^{\prime}\right|+\phi_{2} l_{2}\left|y_{c 2}-y_{c 2}^{\prime}\right|\right) \text {, }
$$

The comparative results obtained by experiment and calculations for the following input parameters: the radius of the drum mill $\mathrm{R}=0.5 \mathrm{~m}$; length of the first chamber $L_{1}=0,65 \mathrm{~m}$; first chamber loading factor of $\varphi_{1}=0.18$; second chamber length $\varphi_{2}=1.3 \mathrm{~m}$; load factor of $L_{2}=0.3 \mathrm{sec}-$ ond chamber; the coefficient of friction of $f=0.4$; bulk density of the grinding road $\quad=4550 \mathrm{~kg} /$ $\mathrm{m} 3$; linear dynamic range and angle to the axis LES mill drum $\alpha=60^{\circ}$; relative speed the mill drum $\psi=0,76$ (corresponds to $45.5 \mathrm{~min}-1$ ). 
Showed that the difference between the experimentally obtained and calculated data as can be seen from the plot (Fig. 5-7) does not exceed $10 \%$. With these values of the input parameters further power consumption calculation was as follows: for the first camera $-62.2 \mathrm{~W}$; to the second chamber - $441.0 \mathrm{~W}$; in general for the mill - 503.2 watts, the experimentally obtained -545 watts.
Analysis of plots obtained (Fig. 5-8), allowed to explore the effect on power consumption of an additional length of the first chamber (the length of the second chamber in this case was such that the sum of the lengths is equal to the length of the chambers of the mill $-1.95 \mathrm{~m}$ ), and the angle of inclination coefficients LEU download cameras grinding bodies.

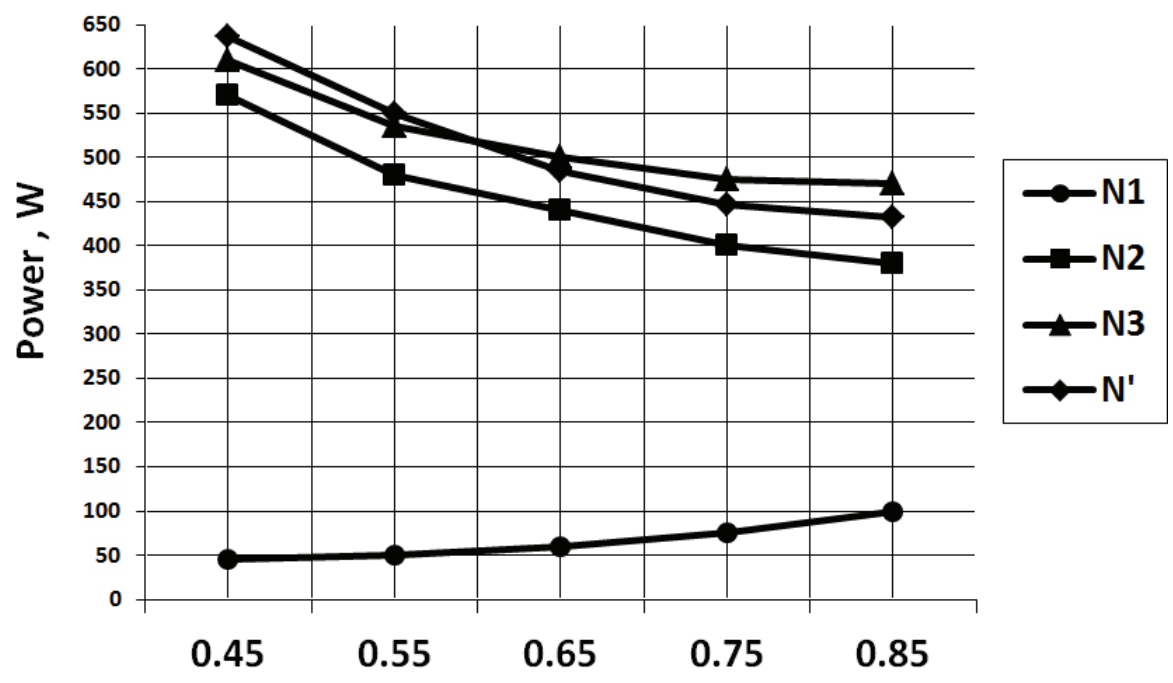

The length of the first chamber, $m$.

Figure 4: Dependence of the additional power consumption of the length of the first chamber

On the charts the following notation: $N_{1}$ and $N_{2}$ more power consumption by moving the grinding load in the first and second chambers, respec- tively $N-$ a total additional power consumption and design $N_{e x}$ - the total power measured experimentally.

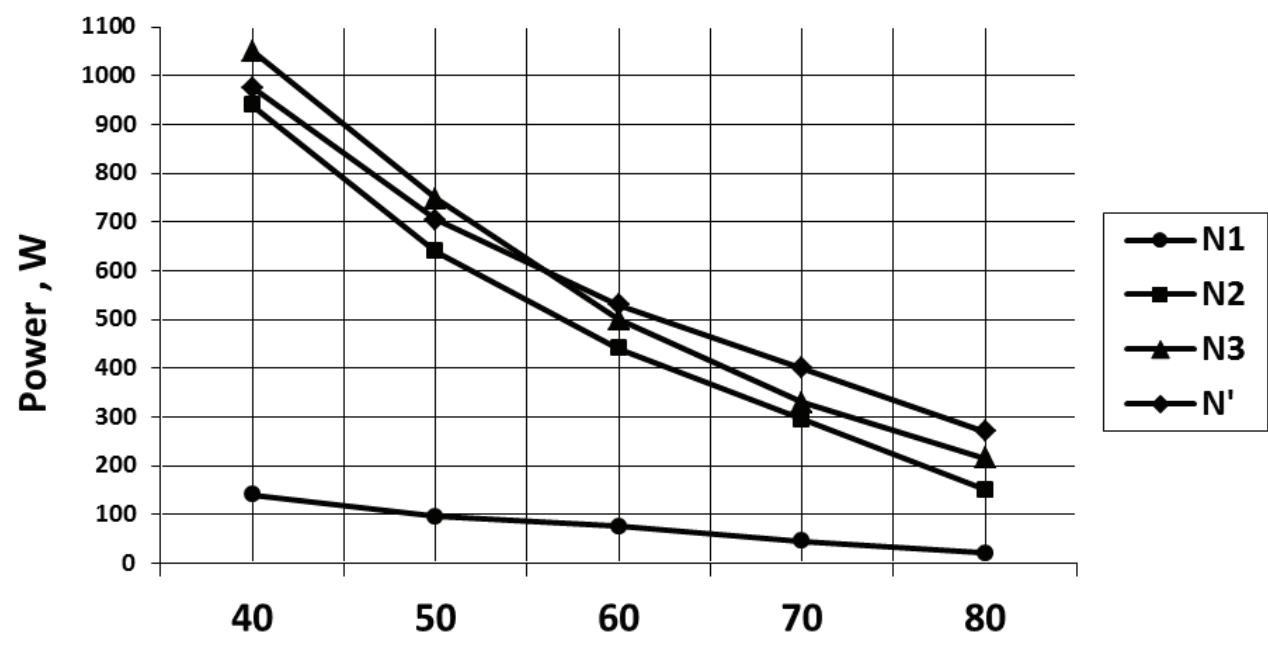

The angle of inclination, degr.

Figure 5: Dependence of the additional power consumption of the linear dynamic range and angle to the axis of the drum LES mill 


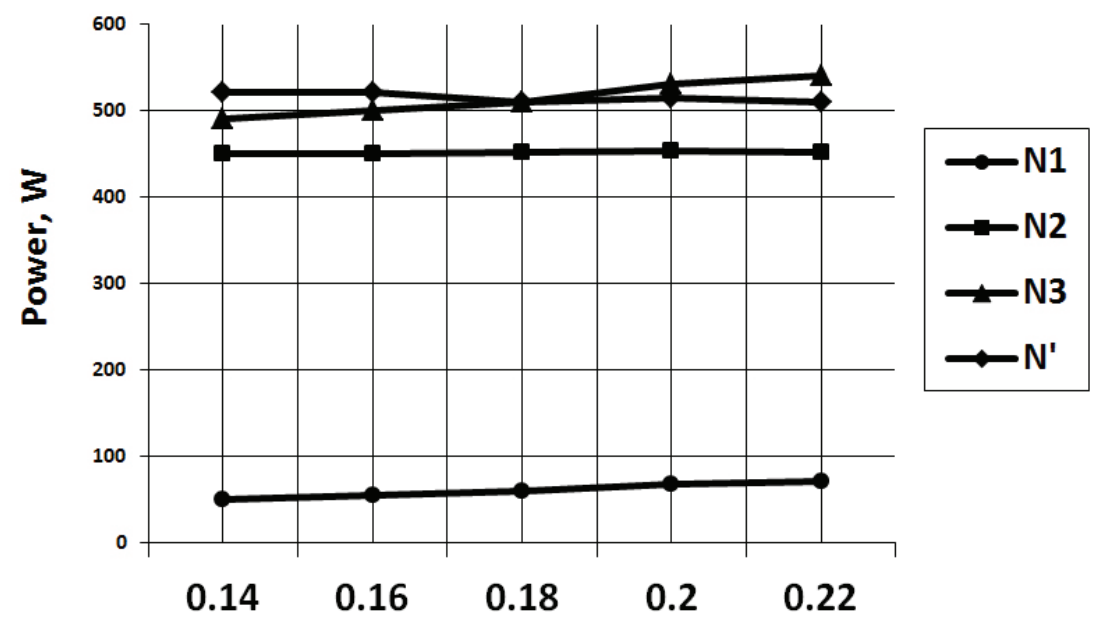

The load factor of the first chamber

Figure 6: Dependence of the additional power consumption of the load factor of the first chamber

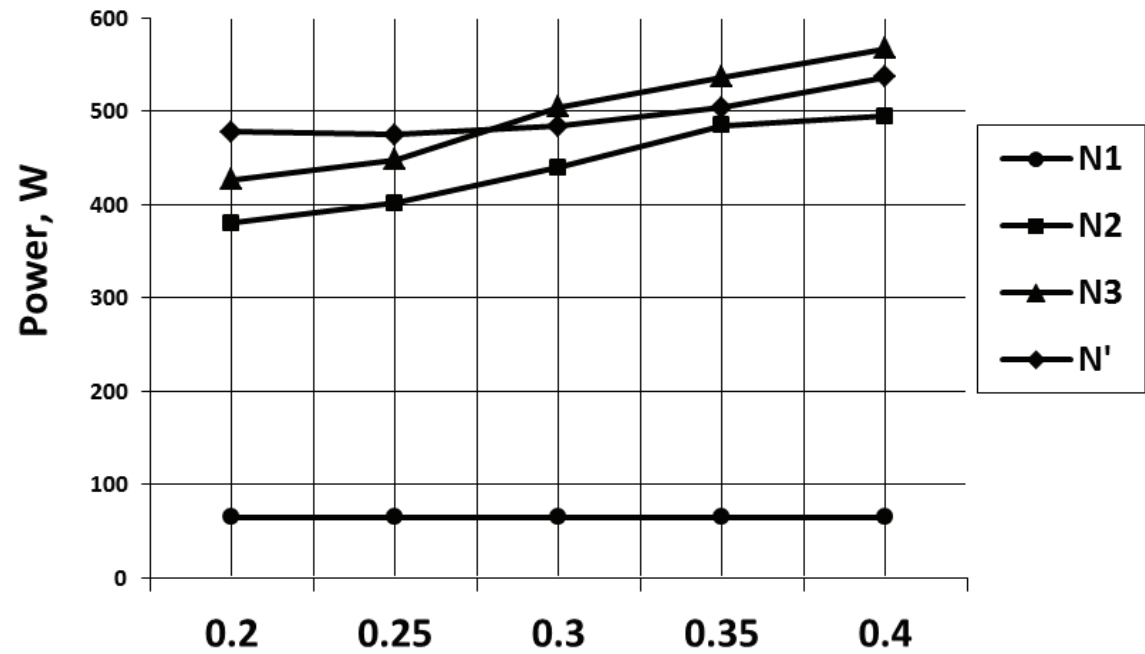

The load factor of the second chamber

Figure 7: Dependence of the additional power consumption of the load factor of the second chamber

As can be seen from the plot (Fig. 5-8) installation in the drum mill energy-exchange devices allows to intensify the work of grinding load, as indicated by the value of the additional power consumption of the drive. Changing the angle of the vane energy exchange devices to the axis of drum mills 40 to 800 reduces the range of the load devices for milling, which reduces the power consumption further. Obtained by the analytical equation with sufficient accuracy reflect the actual process.

\section{CONCLUSION}

Thus, the installation of energy exchange in the drum mill device allows to intensify the work of grinding load, as indicated by the value of the additional drive power consumption and thereby reduce the specific energy consumption and im- prove productivity grinding plant. The presented method of calculating method of power consume additional mill equipped with devices by energy expended on longitudinal movement of the grinding media in the grinding of materials with sufficient accuracy to reflect the real aprotsess.

\section{ACKNOWLEDGEMENTS}

The authors extend acknowledgements to the rector of BSTU, prof. Sergei Nikolaevich Glagolev for their assistance in organizing the study and publication of the results.

*Work has been performed in the framework of Strategic Development Program at BSTU for 2012-2016. 


\section{REFERENCES}

1) Bogdanov, V.S., Sharapov, R.R. and Fadin, Y.M. (2008) Optimization of the grinding process in cement production Intern. Congress of Cement Manufacturers 9-12 October 2008. Belgorod State Technological University named after V.G.Shukhov, M: European tech. Inst, pp. 20-39.

2) Romanovich, A.A. (2011) Energy savings in the manufacture of building products. Scientific and technical journal "Bulletin of BSTU named after V.G.Shukhov", № 3, pp. 69-71.

3) Bogdanov, V.S., Voronov, V.P. and Potapov, F.P. (2011) Calculation of the work expended in the destruction of the material in the cascade operation of the ball mill. Herald of Belgorod State Technological University named after V.G.Shukhov, № 1, pp. 61-64.

4) Bogdanov, V.S. and Romanenko V.S. (2012) Some efforts grinding in roller mills horizontal with regard to the strength of material. Scientific and technical journal "Bulletin of BSTU named after V.G. Shukhov", № 4, pp. 84-87.

5) Romanovich, A.A. (2013) Determination of the center of mass of ball load the first chamber of the mill, equipped with paddle energy exchange devices. Scientific journal "Bulletin of the Novosibirsk State University", № 2 (51), pp. 166-172.

6) Romanovich, A.A. (2013) The issue of calculating the power consumed by the mill with paddle energy exchange devices. Scientific and technical journal "Bulletin of BSTU named after V.G. Shukhov", № 4, pp. 74-77.

7) Rudichev, A., Romanovich, L., Lycheva, A. and Romanovich, M. (2013) Incentives for Innovative Activity of Young Scientists on the Basis of Higher Educational Institutions in Russia. Experience of Belgorod State Technological University named after V.G. Shukhov, World Applied Sciences Journal, № 25 (12), pp. 1754-1757.

8) Romanovich, L., Sevostyanov, V., Romanovich, M. and Sevostyanov, M. (2014) Innovation activity and technology transfer of higher education. Journal of Applied Engineering Science / Istrazivanja i projektovanja za privredu, 4 (13), pp. 273-276.

Paper sent to revision: 20.04.2015.

Paper ready for publication: 15.09.2015. 